\title{
La importancia de Darstellung der antiken Rhetorik en la configuración de la perspectiva retórico-lingüística del joven Nietzsche (1872-1873)
}

\section{The importance of Darstellung der antiken Rhetorik in shaping the rhetorical-linguistic perspective of the young Nietzsche (1872-1873)}

Fernando Fava*

Sebastián Bisang ${ }^{* *}$

Resumen: Entre los años 1869 y 1873, la preocupación de Nietzsche comienza a centrarse en las cuestiones relativas al lenguaje y al conocimiento de forma creciente. Luego de experimentar y ensayar con distintas teorías del lenguaje, Nietzsche adopta el abordaje retórico-lingüístico a partir del año 1872. En efecto, el filósofo alemán primero desarrolla la postura retórica-lingüística en el apunte de clases titulado Descripción de la retórica antigua (Darstellung der antiken Rhetorik - 1872), y un año más tarde, en el célebre texto póstumo Sobre verdad y mentira en sentido extramoral (Wabrbeit und Lüge im aussermoralischen Sinne -1873). No obstante, son escasos los trabajos académicos que se ocupan exhaustivamente del análisis de Descripción de la retórica antigua y, dentro de este grupo de estudios, son más escasos aun los que se basan en la edición crítica de Colli-Montinari. En este contexto, el objeto del presente trabajo se circunscribe al estudio histórico-genético de la perspectiva retórico-lingüística del joven Nietzsche desarrollada en Descripción de la retórica antigua, a fin de mostrar la importancia que la

\footnotetext{
* El presente trabajo fue llevado a cabo en el marco del Programa de Proyectos para Investigadores Formados de la Universidad Católica de Santa Fe. Proyecto "La crítica a la cultura en el joven Nietzsche: lenguaje y conocimiento". Fernando Fava es Licenciado en Filosofía por la Universidad Nacional de Córdoba y Doctor en Filosofía por la Universidad de Málaga y la Universidad Católica de Santa Fe. Se desempeña asimismo como Docente investigador en la Universidad Católica de las Misiones y en la Universidad Nacional de Entre Ríos. Dirección electrónica: ferjfava@hotmail.com ** Licenciado en Filosofía por la Universidad Católica de Santa Fe. Becario doctoral del CONICET, se encuentra realizando su tesis en la Universidad Nacional de Córdoba. Su lugar de trabajo es el Centro de Investigaciones en Filosofía Política y Epistemología (CIFPE) de la Universidad Nacional de Entre Ríos. Dirección electrónica: sebastianbisang@gmail.com
} 
consideración de este escrito tiene para la comprensión de la concepción tropológica del lenguaje del filósofo alemán durante ese período de tiempo.

Palabras clave: Nietzsche, lenguaje, retórica, tropos, metáfora.

Abstract: Between the years 1869 and 1873, Nietzsche's concern begins to focus increasingly on questions of language and knowledge. After experimenting and rehearsing with different theories of language, Nietzsche adopts the rhetoricallinguistic approach from the year 1872. Indeed, the German philosopher first develops the rhetorical-linguistic position in the class note entitled Description of ancient rbetoric (Darstellung der antiken Rhetorik - 1872), and a year later, in the famous posthumous text On truth and lies in an extramoral sense (Wabrheit und Lüge im aussermoralischen Sinne - 1873). However, there are few academic works that deal exhaustively with the analysis of the Description of ancient rhetoric and, within this group of studies, even fewer are based on the critical edition of Colli-Montinari. In this context, the object of the present work consists in the historical-genetic study of the rhetorical-linguistic perspective of the young Nietzsche developed in Description of ancient rhetoric, in order to show the importance that the consideration of this writing has for the understanding of the German philosopher's tropological conception of language during that period of time.

Key Words: Nietzsche, language, rhetoric, tropes, metaphor.

\section{Introducción}

Entre los años 1869 y 1873, la preocupación de Friedrich Nietzsche comienza a centrarse en las cuestiones relativas al lenguaje y al conocimiento de forma creciente. A fin de comprender la relación entre ambos, el pensador alemán experimenta y ensaya con distintas posibilidades y modelos existentes acerca de una posible teorización sobre el lenguaje. En este contexto de búsqueda de la esencia del lenguaje -específicamente a partir de su crisis con la línea romántica schopenhaueriana-wagneriana, las duras polémicas con sus colegas filólogos tras la publicación de El Nacimiento de la Tragedia (Die Geburt der Tragödie) y las influencias de la tradición de filología clásica (A. Westermann, L. Spengel, R. Volkmann y F. Blass) y la tradición filosófico-lingüística (G. Gerber y, a través de él, la lingüística y la filosofía del lenguaje del siglo XIX)Nietzsche adopta el abordaje retórico del lenguaje hacia el año 1872 sobre el horizonte siempre presente de sus preocupaciones relativas al conocimiento. La atención, hasta entonces concedida a la problemática del lenguaje, se 
reorganiza y profundiza desde la perspectiva retórico-lingüística, en tanto vía capaz de expresar sus intuiciones gnoseológicas sobre el carácter arbitrario e ilógico de la génesis de los conceptos y de las categorías de la razón.

En efecto, a partir de 1872, se evidencia una reordenación en el desarrollo del pensamiento de Nietzsche. Como ha señalado Curt Paul Janz, no constituye un cambio tan extremo como pudiera pensarse en un primer momento, sino que, por el contrario, se encuentra en continuidad con sus primeras preocupaciones por el lenguaje como lugar de la crítica a la cultura y a la filosofía. ${ }^{1}$ Este reordenamiento implica un desplazamiento del interés inicial de Nietzsche por el símbolo, el arte y la música hacia la retórica. Ello puede apreciarse en los Escritos sobre retórica y principalmente, en Sobre verdady mentira en sentido extramoral (Wabrheit und Lüge im aussermoralischen Sinne). En ambos escritos, el tratamiento de la problemática del lenguaje, en especial su génesis y desarrollo, es reconducido por la vía de la retórica. A partir de la problematización de los elementos retóricos presentes en el lenguaje, una nueva perspectiva de interpretación comienza a sedimentarse en el pensamiento de Nietzsche, destinada a desenmascarar las ilusiones epistemológicas de la metafísica y la relación lenguaje-conocimiento. ${ }^{2}$

Los Escritos sobre retórica constituyen una compilación de los apuntes de cursos y notas de clases de Nietzsche pertenecientes a su actividad académica en la Universidad de Basilea. El compilado abarca cinco escritos datables entre los años 1872 y 1874: Descripción de la retórica antigua (Darstellung der antiken Rhetorik [semestre de invierno de 1872]), Compendio de la historia de la elocuencia (Abriss der Geschicte der Beredsamkeit [1872]), Historia de la elocuencia griega (Geschichte der griechischen Beredsamkeit [1872-1873]), Notas sobre retórica (verano de 1872 comienzos de 1873) e Introducción a la Retórica de Aristóteles (Einleitung zur Rhetorik des Aristoteles [1874]).

Entre los textos que componen Escritos sobre retórica, Descripción de la retórica antigua (Darstellung der antiken Rhetorik.) -también conocido con el título

${ }^{1}$ Cfr. Janz, Curt Paul: Friedrich Nietzsche. 2. Los diez años de Basilea, trad. Jacobo Muñoz y Isidoro Reguera, Madrid, Alianza, 1981, pp. 142-195.

${ }^{2}$ Cfr. De Santiago Guervós, Luis Enrique: Arte y poder. Aproximación a la estética de Nietzsche, Madrid, Trotta, 2004, p. 402. 
genérico de Curso de Retórica ${ }^{3}$ constituye el primer texto donde Nietzsche desarrolla la cuestión de la retórica de modo sistemático e histórico. Sin embargo, no puede afirmarse que consista en un tratado o en un estudio sobre retórica, sino que -como lo expresa de Santiago Guervós, uno de los mayores estudiosos del tema- constituye "(...) una guía práctica para un curso en que se consignan ejemplos, referencias históricas, citas que puedan servir de recordatorio recurrente ante sus alumnos." ${ }^{4}$ Más precisamente, Descripción de la retórica antigua comporta un claro ejemplo de cómo Nietzsche examina y utiliza el trabajo de sus contemporáneos de acuerdo con sus propios intereses y preocupaciones -en este caso en particular, los estudios filológicos y lingüísticos de su época-, dando lugar así a la producción de un texto que lleva su impronta.

No obstante, los trabajos académicos que se ocupan de forma exhaustiva del estudio de Descripción de la retórica antigua son escasos. La mayor parte de la profusa y variada bibliografía especializada sobre la postura lingüística de Nietzsche durante el periodo en cuestión se basa casi exclusivamente, cuando no totalmente, en Sobre verdad y mentira en sentido extramoral y descuida tratar detenidamente Descripción de la retórica antigua. ${ }^{5}$ Sumado a esto, una buena parte de los trabajos que sí toman en cuenta a Descripción de la retórica antigua como una pieza ineludible de sus análisis, lo hacen

${ }^{3}$ Cfr. De Santiago Guervós, Luis Enrique: "El poder de la palabra: Nietzssche y la retórica" en Nietzsche, Friedrich, Escritos sobre retórica, trad. Luis Enrique de Santiago Guervós, Madrid, Trotta, 2000, p. 16 (nota 24), p. 68.

${ }^{4}$ Ibid., p. 72.

${ }^{5}$ A este respecto pueden mencionarse como excepciones, además de los ya citados de de Santiago Guervós, los siguientes trabajos: Schnyder, Peter, "Ursprungskritik Nietzsches Anfänge und die Ursprünge der Rhetorik", Nietzsche-Studien. Internationales Jahrbuch für die Nietžsche-Forscbung, 2013, núm. 42, pp. 1-20; Sánchez, Sergio: "Lenguaje, conocimiento y verdad en la filosofía del joven Nietzsche: los póstumos de 1873 y sus fuentes", Nombres. Revista de Filosofía, 1999, núm. 13-14, pp. 181-214; Sánchez, Sergio: "Los escritos de Nietzsche sobre retórica en edición española", Nombres. Revista de Filosofía, 2000, núm. 15, pp. 293-297; Sánchez, Sergio, El problema del conocimiento en la filosofía del joven Nietəsche: los póstumos del periodo 1867-1873, Córdoba, Universitas, 2003. 
desde las problemáticas ediciones Kröner $(1912)^{6}$ y Musarion $(1922)^{7}$ que se caracterizan por tener múltiples errores de trascripción y realizar numerosos recortes arbitrarios de los manuscritos originales. ${ }^{8}$

En este contexto, el objeto del presente trabajo se circunscribe al estudio histórico-genético de la perspectiva retórico-lingüística del joven Nietzsche desarrollada en Descripción de la retórica antigua, a fin de mostrar la importancia que la consideración de este escrito tiene para la comprensión de la configuración de la concepción tropológica del lenguaje del filósofo alemán. Para ello, se hace uso aquí de la traducción al español de Descripción de la retórica antigua realizada por Luis Enrique de Santiago Guervós a partir de los textos completos y no tergiversados de la edición de Colli-Montinari ${ }^{9}$. De esta forma, se presenta como elemento o aspecto académicamente relevante, una

${ }^{6}$ Nietzsches Werke (ed. A. Kröner), Leipzig, 1912. Vols. 17, 18, 19 (Philologica, 1, 2, 3), 1912-1913. En lo que respecta a Descripción de la retórica antigua, dicha edición sólo publica las siete primeras secciones de las dieciséis que componen el manuscrito original.

${ }^{7}$ Nietzsches gesammelte Werke (Vorlesungen 1872-1876), vol. 5, München, Musarion, 1922. En esta edición se reproducen sin modificaciones los mismos textos que en la edición de Kröner.

${ }^{8}$ Los estudios de Anthonie Meijers, Martin Stingelin y Claudia Crawford son claros ejemplos al respecto. Cfr. Meijers, Anthonie: "Gustav Berger und Friedrich Nietzsche. Zum historischen Hintergrund der sprachphilosophischen Auffassungen des frühen Nietzsche", Nietzsche Studien, 1988, núm. 17, pp. 371-372; Meijers, Anthonie y Stingelin, Martin, "Konkordanz zu den wörtlichen Abschriften und Übernahmen von Beispielen und Zitaten aus Gustav Gerber. Die Sprache als Kunst (Bomberg, 1871) in Nietzsches Rhetorik-Vorlesung und in Über Wahrheit Lüge im aussermoralischen Sinne", Nietzsche Studien, 1988, núm. 17, p. 350; Stingelin, Martin, "Nietzsche Wortspiel als Reflexion auf poet(olog)ische Verfahren" Nietzssche Studien, 1988, núm. 17, p. 347; y Crawford, Claudia, The beginnings of Nietzsche's theory of language, Berlin, De Gruyter, 1988, p. XXIV, donde se toma la traducción de Descripción de la retórica antigua realizada por Carole Blair en base al limitado texto de las ediciones Kröner y Musarion: cfr. Nietzsche, Friedrich, "Nietzsche's 'Lecture Notes on Rhetoric': A Translation.”, Carole Blair trans., Philosophy \& Rhetoric, Vol. 16, núm. 2. Penn State University Press. 1983, pp. 94-129. Stable URL: http://www.jstor.org/stable/40237356.

${ }^{9}$ La traducción de Descripción de la retórica antigua se basa en Werke, Kritische Gesamtausgabe (KGW), Abd. 2, Bd. 4: Vorlesungsaufzeichnungen: WS 1871-72 - WS 1874-75, Berlin, Walter de Gruyter, 1995, elaborada por Fritz Bormann y Marco Carpitella. 
reconstrucción detallada de los inicios del proceso de configuración de la perspectiva retórico-lingǘstica nietzscheana a partir del texto integral de Descripción de la retórica antigua.

\section{La retórica como arte del lenguaje}

Probablemente, uno de los interrogantes iniciales que podría formularse al momento de comenzar a desarrollar la perspectiva retórico-lingüística nietzscheana es aquel concerniente al tipo de relación o relaciones que son posibles de establecer entre la retórica y el lenguaje. En este orden de ideas, cabría realizar la siguiente pregunta a modo de guía dentro de esa cuestión: ¿cómo Nietzsche opera el pasaje desde la retórica en tanto arte de la elocuencia, la persuasión y la emotividad, es decir, de acuerdo con el modo en cómo tradicionalmente ha sido concebida, hacia la retórica como un modelo o enfoque lingüístico capaz de organizar una crítica a la metafísica clásica y de fundar una nueva visión estética del mundo y del hombre? Es decir, ¿cómo realiza el paso desde "la retórica como arte del lenguaje" hacia "el lenguaje como arte retórico"?

Los primeros indicios de una respuesta pueden rastrearse en el parágrafo inicial de la Descripción de la retórica antigua, titulado "Concepto de retórica". En esa sección, Nietzsche emprende un breve recorrido histórico a lo largo de los diferentes intentos en dar una definición sobre la retórica por varios pensadores antiguos. A diferencia de los autores modernos -quienes, según entiende el pensador alemán, además de ser imprecisos al momento de brindar un concepto claro de la retórica, expresan un notable desprecio por este arte-10, los autores antiguos se abocan intensamente al estudio y desarrollo de la

10 A este respecto, en una nota de Descripción de la retórica antigua Nietzsche cita el siguiente fragmento de John Locke perteneciente a su Ensayo del entendimiento bumano: "Sin embargo, si pretendemos hablar de las cosas como son, es preciso admitir que todo el arte retórico, exceptuando el orden y la claridad, todas las aplicaciones artificiosas y figuradas de las palabras que ha inventado la elocuencia, no sirven sino para insinuar ideas equivocadas, mover las pasiones y para seducir así el juicio, de manera que en verdad no es sino superchería" (Locke, John, Ensayo sobre el entendimiento bumano, trad. Edmundo O’Gorman, México, Fondo de Cultura Económica, 2da ed., 2005, Libro III, Cap. X, \34, p. 503). Cfr. Nietzsche, Friedrich, Escritos sobre retórica, p. 81. 
retórica. Este arte liberal, afirma Nietzsche, “(...) se enraíza en un pueblo que todavía vive entre imágenes míticas y que no conoce aún la necesidad absoluta de la fe histórica; ellos prefieren más bien ser persuadidos que instruidos." 11

Sumado a ello, el perfeccionamiento y la importancia de la retórica se explican en buena medida debido a la necesidad política que el hombre antiguo tiene de dominar la elocuencia jurídica. La retórica constituye un “(...) arte esencialmente republicano"12 para el mundo antiguo:

Uno tiene que estar acostumbrado a soportar las opiniones y los puntos de vista más extraños e incluso a sentir un cierto placer en la contradicción, hay que escuchar con el mismo buen agrado que cuando uno mismo habla, y como oyente hay que ser capaz, más o menos, de apreciar el arte aplicado. La formación del hombre antiguo culmina babitualmente en la retórica: es la suprema actividad espiritual del hombre politico bien formado, juna idea para nosotros muy extraña?'13

Tras esta descripción del rol fundamental que la retórica desempeña en la vida de los antiguos, Nietzsche da inicio al análisis de los diferentes conceptos de la retórica defendidos por los principales filósofos y oradores griegos y romanos, haciendo uso explícito de los trabajos de Leonhard Spengel $(1803-1880)^{14}$ y Richard Volkmann $(1832-1892)^{15}$ para ello. Más específicamente, en esta primera sección de Descripción de la retórica antigua, Nietzsche se apropia de la compilación cronológica que Spengel y Volkmann

${ }^{11}$ Nietzsche, F., Escritos sobre retórica, p. 81. La cursiva es propia.

12 Ibid.

${ }^{13}$ Ibid. La cursiva es propia.

${ }^{14} \mathrm{El}$ trabajo de Leonhard Spengel que Nietzsche utiliza fue publicado en 1863 bajo el título Die Definition und Eintheilung der Rhetorik bei den Alten (La definición y la clasificación de la retórica de los antiguos).

${ }^{15}$ Richard Volkmann publica en 1872 Die Rhetorik der Griechen und Römer in systematischer Übersicht dargestellt (La retórica de los griegos y romanos presentado en una revisión sistemática). De acuerdo con de Santiago Guervós, “(...) esta obra es una de las fuentes principales de Nietzsche para este Curso de retórica, sobre todo en la introducción y la tercera parte. Coinciden algunos títulos de los capítulos, la mayor parte de los ejemplos y a veces copia párrafos enteros" (de Santiago Guervós, Luis Enrique, "El poder de la palabra: Nietzsche y la retórica" en Nietzsche, Friedrich: Escritos sobre retórica, p. 83). 
realizan sobre las discusiones de los antiguos; debates originados con motivo de los variados intentos de elaborar una definición de la retórica.

Estos dos estudios revelan a Nietzsche que, para muchos de los autores griegos, el telos o la meta de la retórica es el $\pi \in \hat{\imath} \theta \in \iota \nu$ o el dicendo persuadere, es decir, la persuasión por el discurso. Así lo entienden los sicilianos Corax y Tisias que afirman “(...) que la artífice o creador de persuasión]."16 También, Gorgias e Isócrates la conciben en un sentido similar. En efecto, “(...) este último la transcribe más

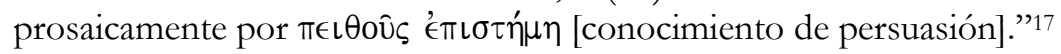

Nietzsche se detiene en el estudio de la postura de Platón. El filósofo alemán dedica varias líneas a comparar numerosos pasajes de los diferentes diálogos platónicos, a fin de señalar las transformaciones que su concepción sobre la retórica ha sufrido a lo largo de toda su obra. Nietzsche comienza su análisis con un fragmento clásico del Gorgias (463b), donde Platón describe una noción netamente negativa de la retórica. Allí, el pensador ateniense define a la

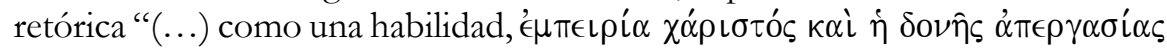
[experiencia de una cierta gracia y agradable en expresión]"18 y la coloca al mismo nivel que el arte culinario, el arte de la cosmética y la sofística del halago. Sin embargo, en el Fedro (259e ss.), Platón exige una preparación profunda y extensa para todo aquel que procure formarse en el verdadero arte de la retórica. Esta preparación, que supera ampliamente las artes con las que la oratoria es comparada en el pasaje del Gorgias, demanda al orador tanto la posesión de la verdad obtenida a través del uso de la dialéctica -a fin de introducir las diversas cuestiones de forma adecuada en la exposición y poder “(...) dominar también lo verosímil y poder embaucar a sus oyentes"-19, como el conocimiento del alma humana y los efectos de los diferentes tipos de discursos sobre el espíritu -con el objeto de poder "(...) excitar las pasiones de sus oyentes y de este modo ejercer un dominio sobre ellos.” ${ }^{20} \mathrm{El}$ hecho “(...)

\footnotetext{
${ }^{16}$ Nietzsche, F., Escritos sobre retórica, p. 83. Corax y Tisias suelen ser considerados como los fundadores de la retórica en Siracusa hacia el año 460 a.C. aproximadamente. Tisias fue discípulo de Corax y maestro de Lisias e Isócrates.

17 Ibid.

18 Ibid.

19 Ibid.

20 Ibid.
} 
de que la tarea del orador sea persuadir a sus oyentes apoyándose en lo verosímil no modifica en nada estos presupuestos." 21 En este sentido, de acuerdo con Platón, el sabio puede ser tanto retórico como filósofo. A pesar de que la meta de la dialéctica es la más elevada, ${ }^{22}$ ello no excluye todo uso y aplicación de la retórica. "No obstante, ¡no puede convertirse en una ocupación seria en la vida!'23

En el Político, Platón reconoce un lugar importante a la retórica en la enseñanza. En el pasaje 304d afirma que el verdadero filósofo, es decir Sócrates, puede enseñar de dos maneras distintas: por un lado, de manera científica; y por el otro, de manera retórico-popular. La finalidad de la enseñanza de forma retórica es la de persuadir a las multitudes y a las muchedumbres a través de las mitologías. El componente mítico presente en los diálogos platónicos, sostiene Nietzsche, es el retórico: “(...) el mito tiene como contenido lo verosímil; su objetivo no es, por consiguiente, enseñar sino suscitar en los oyentes una $\delta o ́ \xi \alpha$ [opinión], por lo tanto $\pi \epsilon i \theta \epsilon \nu \nu$ [persuadir]”. ${ }^{24}$ Lo mítico y lo retórico se utilizan cuando la escasez de tiempo torna imposible una enseñanza científica. De este modo, si bien Platón reconoce a la retórica una función válida, ésta no puede enseñar o instruir sobre la verdad, quedando así delimitado su espacio de competencia exclusivamente a lo verosímil, a la opinión y al uso de la persuasión.

En la República, Platón señala uno de los objetivos específicos de este tipo de enseñanza persuasiva. En el pasaje 376e distingue dos tipos de discursos: aquellos que contienen verdad y aquellos otros que mienten. Los mitos se enrolan dentro de estos últimos. Sin embargo, ello no implica el rechazo de lleno a los mitos. Platón entiende "(...) que los mitos son justificables y reprocha a Hesíodo y a Homero no precisamente que ellos mintiesen, sino que no lo hicieran de manera correcta." 25 En efecto, en el pasaje 389 b, el filósofo ateniense rescata su valor político cuando dice "(...) que las

\footnotetext{
${ }^{21}$ Ibid., p. 84. La cursiva es propia.

22 "Por eso explica Sócrates en 273e, que quien ha alcanzado esta cima del saber, no se contentará ya con tareas más bajas: la meta más alta es, entonces «la comunicación a otros del conocimiento adquirido»." (Ibid.)

23 Ibid.

24 Ibid.

25 Ibid.
} 
mentiras son útiles para el ser humano en determinadas circunstancias y que debe de estar permitido a los gobernantes servirse de ellas para el bien de sus ciudadanos". 26 En el mismo sentido, en el pasaje 414b, Nietzsche sostiene que Platón "(...) introduce un mito completo para establecer una opinión especifica en el alma de los ciudadanos, y para este fin no evita la mentira como un medio retórico". ${ }^{27}$ En conclusión, Nietzsche afirma:

La polémica de Platón contra la retórica se dirige en primer lugar contra los fines perniciosos de la retórica popular, luego contra la preparación completamente ruda, insuficiente y no filosófica del orador. Sólo le otorga un cierto valor cuando se basa en una formación filosófica y se aplica a fines justos, es decir, a los fines de la filosofía. ${ }^{28}$

A pesar de estas consideraciones sobre la retórica, la antigüedad no cuenta con una obra que trate exclusivamente este arte del lenguaje hasta el siglo IV a.C. En este siglo es cuando dos textos clásicos sobre esta materia aparecen. El primero de ellos es la Rhetorica ad Alexandrum del retórico Anaxímenes de Lampsaco. Nietzsche le resta importancia a esta obra dado que se encuentra "(...) completamente orientada al uso práctico, no es en absoluto filosófica y básicamente sigue la doctrina de Isócrates." 29 Además, “(...) no se da ninguna

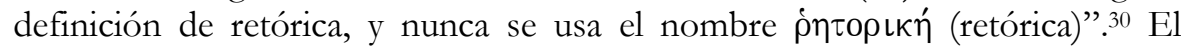
segundo texto de retórica al que Nietzsche hace referencia es la Retórica de Aristóteles. El filósofo alemán lo caracteriza como una obra puramente filosófica, cuya influencia se torna decisiva en las futuras determinaciones del concepto de retórica. En el capítulo II perteneciente a la Primera Parte del Libro I, Aristóteles da su célebre definición de la retórica, que Nietzsche trascribe del

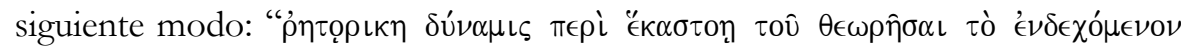
$\pi \iota \theta \alpha \nu o ́ v$ [retórica es la facultad de observar todos los posibles medios de

\footnotetext{
${ }^{26}$ Ibid. La cursiva es propia.

${ }^{27}$ Ibid. La cursiva es propia.

${ }^{28}$ Ibid. La cursiva es propia.

${ }^{29}$ Ibid., p. 85.

${ }^{30} \mathrm{Ibid}$.
} 
persuasión sobre cada cosa], «todo aquello que es posiblemente verosímil y convincente» (Aristóteles, Retórica, I, 2)".31

Esta definición excluye dos cosas desde el comienzo: primero, la retórica no es una episteme, es decir, no es un conocimiento científico sobre la verdad de las cosas; y segundo, la retórica tampoco es una tekne, en el sentido de una práctica empírica carente de una reflexión filosófica radical sobre su meta o su telos, es decir, sobre el concepto de lo persuasivo. Al igual que lo ha hecho Platón al hablar del componente mítico de sus diálogos en el Político (304d), Aristóteles establece una íntima conexión entre la persuasión y la verosimilitud que más adelante Nietzsche explicita: "Aristóteles (Tópicos, I, 12) dice que una cosa se trata filosóficamente en función de la verdad, dialécticamente en función de la apariencia o aprobación, es decir, según la $\delta o ́ \xi \alpha$ [opinión] de otros. Se podría decir lo mismo de la retórica." 32

En sintonía con el pensamiento nietzscheano, Paul Ricoeur señala que “(...) el mérito de Aristóteles fue elaborar este vínculo entre el concepto retórico y el concepto lógico de lo verosímil y construir sobre esta relación todo el edificio de la retórica filosófica." 33 El Estagirita ha advertido claramente sobre los peligros que la retórica entraña constantemente de eximirse de la preocupación por el deber de decir la verdad. Ello lo lleva a recurrir al uso lógico del término de "lo verosímil" (to eikos), puesto que le otorga un título legítimo al uso público de la palabra al cual puede acogerse. La retórica -de acuerdo con Aristóteles- no demanda un tipo de prueba de carácter necesario, propio de la geometría o de la filosofía fundamental; sino más bien, uno de naturaleza verosímil. Los asuntos humanos que son objeto de discusión y debate en los tribunales y asambleas de la antigua Atenas no son susceptibles de ser comprehendidos bajo las exigencias de los mecanismos y constricciones intelectuales de la filosofía primera. Por lo tanto, “( ...) en vez de denunciar la doxa (opinión) como inferior a la episteme (ciencia), la filosofía puede proponerse elaborar una teoría de lo verosímil que proteja a la retórica

\footnotetext{
31 Ibid. Nietzsche añade a la definición el término "verosímil" que Aristóteles no incorpora en este fragmento, pero que sí utiliza más adelante. Cfr. Aristóteles, El arte de la retórica, trad. E. Ignacio Granero, Buenos Aires, Eudeba, 2da. ed., 2015, p. 44.

${ }^{32}$ Nietzsche, F. Escritos sobre retórica, p. 86. La cursiva es propia.

${ }^{33}$ Ricoeur, Paul, La metáfora viva, trad. Agustín Neira, Madrid, Trotta-Cristiandad, 2da. ed., 2001, p. 19.
} 
frente a sus propios abusos, disociándola de la sofistica y de la erística." 34 Por este motivo, Ricoeur concluye que “(...) la retórica de Aristóteles constituye la más brillante de las tentativas de institucionalizar la retórica partiendo de la filosofía." 35

Luego, el pensador alemán señala cómo la preocupación de los antiguos se centra en incorporar los componentes de la elocutio, la dispositio, la memoria y la pronuntiatio a la definición de retórica tras las críticas formuladas a la Retórica de Aristóteles. En efecto, los retóricos posteriores al Estagirita le reprochan que ha tenido en cuenta únicamente la inventio - la retórica concebida como la facultad de observar, analizar o contemplar $(\theta \epsilon \omega \rho \hat{\eta} \sigma \alpha \iota)^{36}$ todos los medios de persuasión- y ha dejado de lado todos estos otros aspectos. He aquí la razón de los esfuerzos posteriores de los estoicos, de Rufo ${ }^{37}$, de Teodoro de Gadara ${ }^{38}$ y del célebre Marco Fabio Quintiliano ${ }^{39}$, en completar el concepto dado por Aristóteles. Es este último quién elabora una definición de la retórica que incorpora los cincos elementos en cuestión: "O bien, para resumirlo en una definición, decimos que la retórica es la ciencia del bien decir, o bien distinguiendo sus partes, que la retórica es la ciencia de la invención, de la disposición y de la elocución correctas, con la seguridad de la memoria y de la nobleza de la actitud". 40

Nietzsche finaliza su recorrido histórico por el pensamiento de los autores antiguos griegos y romanos con las figuras de Hérmagoras, Cornificio y Cicerón. De acuerdo con el filósofo alemán, Hérmagoras ${ }^{41}$ delimita la

\footnotetext{
34 Ibid.

35 Ibid., p. 18.

${ }^{36} \mathrm{El}$ verbo griego $\theta \epsilon \omega \rho \epsilon ́ \omega$ que Aristóteles utiliza en su concepto de retórica admite todas estas acepciones que Nietzsche opta por usar en Descripción de la retórica antigua. Cfr. Liddell, Henry George y Scott, Robert: A Greek-English Lexicon. Revised and augmented throughout by Sir Henry Stuart Jones, with the assistance of Roderick McKenzie. Oxford, Clarendon Press, 9na. ed., 1996, p. 673.

37 Retórico del siglo I d.C.

38 Retórico del siglo I d.C, maestro de retórica del emperador romano Tiberio.

${ }^{39}$ Retórico del siglo I d.C, autor de la famosa obra en doce libros titulada De institutione oratoria. Las citas y referencias que Nietzsche realiza de Quintiliano corresponden en su mayoría a esta obra.

${ }^{40}$ Nietzsche, F., Escritos sobre retórica, p. 86.

${ }^{41}$ Retórico del siglo II d.C., maestro de Cicerón.
} 


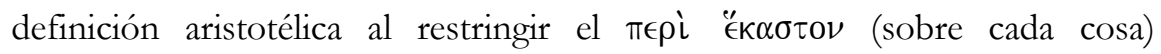
únicamente a los asuntos políticos, “(...) a fin de excluir tanto las investigaciones filosóficas como las relativas a las ciencias particulares." 42 Respecto al Auctor ad Herennium de Cornificio y los escritos de Cicerón, Nietzsche afirma que constituyen las adaptaciones latinas de las dos grandes obras griegas de Anaxímenes y Aristóteles. Del conjunto de las obras de Cicerón, Nietzsche menciona las siguientes: De inventione, texto de juventud que sigue las fuentes griegas; De oratore, escrito de madurez que "(...) comparado con el de Aristóteles, es burdo e inútil”"43; Brutus, “(...) una caracterización inestimable de célebres oradores de Roma" "44; Orator, donde se afirma que “(...) el perfectus orator se encuentra en la elocutio" "45; y finalmente, Tópico, un escrito destinado al jurista Trebacio que procura ser un resumen de la obra aristotélica.

\section{E1 lenguaje como resultado de artes puramente retóricas (lauter rhetorischen Künsten)}

La Retórica de Aristóteles tiene un rol fundamental en la historia del concepto de retórica que Nietzsche desarrolla a partir de los estudios de Spengel y Volkmann. El Estagirita -al tiempo que recibe y se apropia de muchos de los elementos de sus antecesores (especialmente, de aquellos pertenecientes a Platón) - se convierte en una referencia obligada para el resto de los autores antiguos que lo suceden, tanto griegos como romanos, una referencia desde donde señalar sus acuerdos $\mathrm{y}$, principalmente, desde donde plantear sus diferencias. Nietzsche se percata de la centralidad de los desarrollos de Aristóteles en esta materia ${ }^{46}$ y hace uso de la definición del Estagirita para expresar la ampliación de la retórica hasta la esencia misma del lenguaje. En

\footnotetext{
${ }^{42}$ Nietzsche, F., Escritos sobre retórica, p. 87.

43 Ibid.

44 Ibid.

45 Ibid. La cursiva es propia.

${ }^{46}$ Cabe remarcar como muestra de este hecho que, además de los escritos sobre retórica de Nietzsche donde el Estagirita es constantemente mencionado, el filósofo alemán realiza una traducción al alemán del libro tercero de la Retórica de Aristóteles entre los años 1874 y 1878 .
} 
efecto, “(...) aquello que Aristóteles proponía bajo el nombre de retórica, como un poder particular del discurso, he aquí que esta definición se eleva a rango de definición esencial del lenguaje." 47

El paso de la retórica como arte persuasivo del lenguaje hacia el lenguaje como arte retórico, Nietzsche lo desarrolla en el tercer parágrafo de Descripción de la retórica antigua, titulado "Relación de la retórica con el lenguaje". Aquí, tras discutir brevemente la concepción peyorativa y empobrecida que los modernos poseen de lo "retórico", es decir, del uso de los artificios (Kunstmittel) retóricos o de los tropos ${ }^{48}$; Nietzsche adelanta su tesis central sobre el carácter retórico del lenguaje:

Sin embargo, no es difícil probar con la luz clara del entendimiento, que lo que se llama "retórico", como medio de un arte consciente, había sido activo como medio de un arte inconsciente en el lenguaje y en su desarrollo, e incluso que la retórica es un perfeccionamiento de los artificios presentes ya en el lenguaje. No hay ninguna «naturaleza» no retórica del lenguaje a la que se pueda apelar: el lenguaje mismo es el resultado de artes puramente retóricas [lauter rbetorischen Künsten]. ${ }^{49}$

De acuerdo con de Santiago Guervós, Nietzsche parte aquí de una distinción conceptual previa “(...) entre la retórica entendida como una aplicación persuasiva del lenguaje, y la retórica entendida como clave metódica para la genealogía y pragmática del lenguaje." ${ }^{50}$ En el primer sentido, se trataría

\footnotetext{
${ }^{47}$ De Santiago Guervós, L. E., Arte y poder. Aproximación a la estética de Nietžsche, p. 388. 48 A este respecto, Nietzsche comienza la sección tercera de la siguiente forma: "Llamamos a un autor, a un libro o a un estilo «retórico» cuando observamos en ellos un uso constante de artificios (Kunstmitell) del discurso; y esto siempre con matiz peyorativo. Pensamos que estamos ante algo que no es natural y tenemos la sensación de que es algo forzado. Obviamente, depende mucho del gusto del que juzga y de lo que para él es exactamente «natural». En general, toda la literatura antigua, y sobre todo la literatura romana, nos parece a nosotros, que manejamos la lengua de manera groseramente empírica, como algo artificial y retórico" (Nietzsche, F., Escritos sobre retórica, pp. 90-91. Y luego (p. 92) sostiene: "Los artificios más importantes de la retórica son los tropos". Los tropos se dividen en: metáfora, metonimia y sinécdoque. ${ }^{49}$ Ibid.

${ }^{50}$ De Santiago Guervós, L. E., Arte y poder. Aproximación a la estética de Nietzsche, pp. 391392.
} 
de la retórica como arte del lenguaje o como desarrollo de los medios artísticos que ya se encuentran presentes en el lenguaje. En el segundo sentido, la retórica concebida “ (...) como la forma más consciente y artificial de aplicación de este medio artístico del lenguaje, representa el instrumento metódico para descubrir heurísticamente su «inconsciente» en el lenguaje, y de este modo reconstruir el lenguaje como «resultado de artes puramente retóricas»". ${ }^{51}$ Esta diferenciación permitiría a Nietzsche comprender la retórica de dos modos distintos, pero no excluyentes: por un lado, como "un arte consciente", del modo en cómo los antiguos la practican; y por el otro, como "un arte inconsciente", en un sentido mucho más amplio, más universal que el primero.

De acuerdo con Nietzsche, los medios de este arte inconsciente, es decir, los llamados tropos o artificios retóricos, ya se encuentran activos en el lenguaje, en especial en lo concerniente a su desarrollo, mucho antes de su uso y perfeccionamiento consciente. Los tropos retóricos como la metáfora, la metonimia o la sinécdoque no son entendidos por Nietzsche como frutos exclusivamente obtenidos por medio de un trabajo de estilización lingüística deliberadamente llevado a cabo por un arte consciente, sino, más bien, como artificios que intervienen en el proceso mismo de formación del lenguaje desde un primer principio y, por lo tanto, se encuentran presentes con anterioridad a su práctica consciente. Tiempo más tarde, estos artificios son refinados tornando posible el surgimiento de la retórica como arte consciente de la persuasión. Ello permite a Nietzsche explicar el lenguaje como el producto de "artes puramente retóricas" de carácter inconsciente. De esta forma, al comprender la génesis del lenguaje como el resultado de la acción de los tropos retóricos de un arte inconsciente, queda vedada la posibilidad de la existencia de una "«naturaleza» no retórica del lenguaje a la que se pueda apelar." Para Nietzsche, no existe una cosa tal como un "lenguaje natural" que sea capaz de expresar el mundo del modo en cómo es en sí mismo.

En continuidad con las ideas de Arthur Schopenhauer, Friedrich A. Lange y Karl R. E. von Hartmann, Nietzsche sostiene una noción del inconsciente de raíz romántica. El inconsciente realiza una actividad de carácter artístico que es responsable de la producción del lenguaje. ${ }^{52}$ La concepción del

\footnotetext{
51 Ibid.

52 Para una mayor profundización sobre la recepción de estos autores en el pensamiento del joven Nietzsche y cómo toma de éstos los primeros elementos a partir
} 
lenguaje como un producto del instinto artístico inconsciente es una postura bastante común de mediados y finales del siglo XIX que Nietzsche conoce con anterioridad a la producción de Descripción de la retórica antigua. ${ }^{53}$ Sin embargo, en Descripción de la retórica antigua (a diferencia de textos y fragmentos anteriores a 1872), la dinámica de la actividad inconsciente como fuente del lenguaje ya no responde solo a los lineamientos del arte en general, sino que ahora, el pensador alemán la delimita dentro del marco de la retórica:

El poder de descubrir y hacer valer para cada cosa lo que actúa e impresiona, esa fuerza que Aristóteles llama «retórica», es al mismo tiempo la esencia del lenguaje: éste, lo mismo que la retórica, tiene una relación mínima con lo verdadero, con la esencia de las cosas; el lenguaje no quiere instruir sino transmitir (übertragen) a otro una emoción y una aprehensión subjetiva. ${ }^{54}$

Al igual que la retórica en tanto arte de la persuasión, el lenguaje no busca comunicar lo que las cosas son, es decir, su finalidad no es instruir sino "transmitir (übertragen) a otro una emoción y una aprehensión subjetiva." El lenguaje no constituye una episteme, no expresa lo que las cosas son en su esencia y verdad. Por el contrario, el lenguaje se revela ahora como una doxa, como una opinión o una ilusión. Retórica y lenguaje comparten así la misma meta, el mismo telos: la persuasión.

No obstante, cabe preguntarse aquí por la razón de esta "limitación” del lenguaje que Nietzsche describe en comparación con los modelos lingüísticos correspondentistas de corte tradicional. Es decir, ¿por qué el lenguaje "tiene una relación mínima con lo verdadero, con la esencia de las cosas"? Nietzsche responde a esta pregunta central dando los primeros esbozos de su concepción sobre la génesis del lenguaje:

de los cuales aborda la problemática del lenguaje desde el inconsciente, lo instintivo, el arte y el conocimiento, ver Fava, Fernando: "Orígenes de la crítica nietzscheana del conocimiento a partir del lenguaje”, Open Insight, Volumen VIII, núm. 13 (enero-junio 2017), pp. 161-188

${ }^{53}$ Cfr. de Santiago Guervós, Luis Enrique: "Nietzsche y los límites del lenguaje: la fuerza del instinto", Philosophica Malacitana: Actualidad de Nietzsche en el 150 aniversario de su nacimiento, Suplemento $N^{\circ} 2,1994$, pp. 122-125.

${ }^{54}$ Nietzsche, F., Escritos sobre retórica, p. 91. 
El hombre que configura el lenguaje no percibe cosas o eventos, sino impulsos (Reize): él no transmite sensaciones, sino sólo copias de sensaciones. La sensación, suscitada a través de una excitación nerviosa, no capta la cosa misma: esta sensación es representada externamente a través de una imagen. Pero hay que preguntarse, sin embargo, cómo un acto del alma puede ser representado a través de una imagen sonora (Tonbild). Para que tenga lugar una reproducción completamente exacta, ¿no debería ante todo ser lo mismo el material en el que debe ser reproducido que aquel en el que el alma trabaja? Sin embargo, puesto que es algo extraño -el sonido- ¿cómo puede entonces producirse algo más adecuado que una imagen?55

Poco tiempo más tarde, Nietzsche describe la génesis del lenguaje con mayor grado de detalle en Sobre verdad y mentira en sentido extramoral, atendiendo especialmente a las distintas fases que forman parte de este complejo proceso genético lingüístico. Sin embargo, aquí ya es posible apreciar elementos centrales de su concepción sobre el desarrollo del lenguaje. En concordancia nuevamente con sus principales influencias, Nietzsche concibe la formación del lenguaje como un proceso gradual de traslación entre esferas de distinta naturaleza. ${ }^{56}$ En efecto, de acuerdo con el pensador alemán, "la cosa misma" genera una excitación nerviosa en el hombre que da lugar a una sensación. Luego, esta sensación, también llamada "acto del alma", es "representada externamente a través de una imagen" o, más específicamente, por medio de "una imagen sonora (Tonbild)". En este pasaje desde el estímulo nervioso a la

\footnotetext{
55 Ibid.

${ }^{56}$ Esta idea de que la génesis del lenguaje se explica como una traslación de una imagen a otra de diferente naturaleza, Nietzsche la encuentra primeramente en Schopenhauer con su caracterización de los conceptos como representaciones de segundo orden o como representaciones de representaciones; más tarde en Lange con su hipótesis de las inferencias inconscientes en respuesta a la pregunta sobre cómo se produce el movimiento de los estímulos a las representaciones abstractas; y finalmente, en Hartmann con su afirmación de que las operaciones de orden inconsciente están destinadas a dar cuenta de la transición operada desde la percepción sensible hasta el pensamiento abstracto. En este punto los tres pensadores se ocupan de lo mismo, es decir, del salto que se produce de una esfera, inconsciente e intuitiva, a otra, consciente y discursiva.
} 
sensación y desde la sensación a la imagen sonora, se opera un movimiento desde dimensiones de diferente carácter. Como consecuencia, ello trae aparejado la imposibilidad del lenguaje de poder describir lo que las cosas son en su propia esencia. Esta imposibilidad radica en los diferentes materiales correspondientes a cada una de estas dimensiones. Para que una reproducción sea "completamente exacta" debe poseer el mismo material que el original que procura reproducir. Por este motivo, la imagen sonora no puede reproducir adecuadamente la sensación. El material de la imagen sonora, es decir, el sonido, es diferente; es "algo extraño" al material de la sensación, afirma Nietzsche.

A todos estos aspectos concernientes al proceso de formación lingüística, Nietzsche agrega este otro poco más adelante:

Los artificios más importantes de la retórica son los tropos, las designaciones impropias. Pero todas las palabras son en sí y desde el principio, en cuanto a su significación, tropos. En vez de aquello que tiene lugar verdaderamente, presentan una imagen sonora que se evanesce con el tiempo: el lenguaje nunca expresa algo de modo completo, sino que exhibe solamente una señal que le parece predominante. (...) In summa: los tropos no se añaden ocasionalmente a las palabras, sino que constituyen su naturaleza más propia. No se puede hablar en absoluto de una "significación propia", que es transpuesta a otra cosa sólo en determinados casos. ${ }^{57}$

Es preciso advertir que cuando Nietzsche habla de tropos lo suele hacer en dos sentidos: por un lado, en un sentido restringido, donde delimita el uso del término tropos exclusivamente al campo de las palabras. Y por otro, en un sentido amplio, donde extiende el uso a otras dimensiones además de la esfera de las palabras.

Respecto al sentido restringido, Nietzsche entiende que un tropo es una transposición impropia de palabras, es decir, una sustitución de una palabra por otra palabra con sentido figurado. En el parágrafo VIII, excluido por las ediciones Kröner (1912) y Musarion (1922), Nietzsche con el fin de señalar la diferencia entre los tropos y las figuras retóricas afirma que “(...) en los tropos

${ }^{57}$ Nietzsche, F., Escritos sobre retórica, pp. 92-93. La cursiva es propia. 
se trata de transposiciones: unas palabras son usadas en vez de otras: lo impropio en lugar de lo propio." 58

Los tropos pueden ser de varias especies: sinécdoques, metáforas y metonimias. En la sinécdoque una cosa es designada con el nombre de otra ya sea aplicando a un todo el nombre de una de sus partes o a una de las partes el nombre del todo que conforma o a un género el nombre de una de sus especies o a una especie el nombre del género que la comprehende o una cosa el nombre de la materia que la compone, etc. Por ejemplo, “(...) cuando el retórico dice «vela» en vez de «barco», «ola» en lugar de «mar»»". ${ }^{59}$ En el caso de la metáfora,

${ }^{58}$ Ibid., p. 114. Respecto a la diferencia entre los tropos y las figuras retóricas, Nietzsche afirma: "En las figuras no hay transposiciones. Son formas de expresión artísticamente cambiadas, desviaciones de lo que es usual, pero no transposiciones. (...) Variantes de las formaciones de oraciones, que, sin una diferencia esencial en el significado, aparecen según su forma, en parte como incremento, en parte como disminución, en parte como cambio de los medios de expresión que de otro modo son regulares y usuales. Varias figuras y formaciones fónicas tienen el mismo significado, es decir, el alma es estimulada para formar la misma idea. El «significado» no quiere decir más que esto: ninguna expresión determina y delimita un movimiento del alma con tal rigidez que pudiese ser considerada como la representación propia del significado. Toda expresión no es más que un símbolo. Las cosas y los símbolos no pueden sustituirse uno por otro. Siempre queda la posibilidad de una elección" (Ibid., p. 114). De acuerdo con Nietzsche, las figuras retóricas interpretan un papel fundamental en el desarrollo de la gramática: "De la misma manera en que hay una mínima diferencia entre las propias palabras y los tropos, también la hay entre el discurso normal y las llamadas figuras retóricas. (...) Pero las formas de la enálage, hipálage y pleonasmo [especies de figuras retóricas] son activas en el desarrollo de la lengua, de la frase; toda la gramática es el producto de lo que se llama figurae sermonis" (Ibid., p. 93. La cursiva es propia).

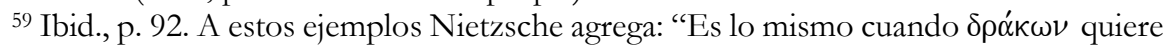
decir serpiente, es decir, literalmente «el que tiene mirada brillante», o bien cuando serpens designa serpiente como aquello que repta; pero, ¿por qué serpens no quiere decir también caracol? Se introduce una percepción parcial en lugar de la plena y completa visión. Por anguis el latín designa serpiente como contrictor, los hebreos la llaman lo que cuchichea o lo que se retuerce, lo que se entrelaza, lo que se arrastra" (Ibid. La cursiva es propia). En este caso, la cosa en cuestión, es decir la serpiente, es designada con el nombre de un determinado atributo o facultad -tener la mirada brillante, el reptar, la constricción, el cuchichear, el retorcerse, el entrelazarse, el arrastrarse, etc.- cuya elección varía acorde a quien o a quienes la impongan. Tanto estos ejemplos como los siguientes de 
se produce una traslación del sentido recto de una voz a otro figurado gracias a una comparación tácita. La metáfora “(...) no produce nuevas palabras, pero les da un nuevo significado." 60 Por ejemplo, “(...) para una montaña se habla de cima, pie, espalda, garganta, picos, vetas." ${ }_{11}$ Y por último, en la metonimia se produce una “(...) sustitución de la causa y del efecto." 62 Por ejemplo, “(...) cuando el retórico dice «sudor» por «trabajo», «lengua» (Zunge) por lenguaje (Sprache)". ${ }^{63}$

Sin embargo, cuando Nietzsche -en clara consonancia con el modelo tropológico de Gustav Gerber- ${ }^{64}$ sostiene que todas las palabras son tropos desde su primer comienzo, hace uso del término tropos en un sentido más amplio que el anterior. En este segundo sentido, Nietzsche concibe los tropos también como transposiciones impropias, pero entre esferas o dimensiones de distinta naturaleza, es decir, sin limitar las traslaciones al exclusivo ámbito de las palabras. De esta forma, es posible explicar el pasaje que se produce desde la sensación a la imagen, sonido o palabra como una trasposición impropia. El carácter impropio de la transposición en este caso se debe a que cuando la palabra pasa a significar la sensación que procura representar, lo hace de un modo tal que nunca expresa completamente a esta última, sino que sólo

los diferentes tropos retóricos son tomados por Nietzsche de las largas listas elaboradas por Gerber en El lenguaje como arte (Die Sprache als Kunst).

60 Ibid.

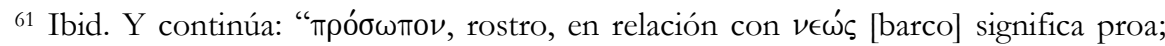

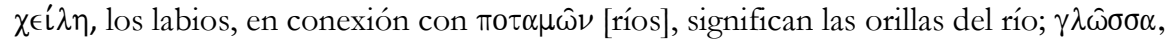
lengua, pero también significa la coembocadura de la flauta; $\mu \alpha \sigma \tau o ́ s$, seno, pero también significa la colina" (Ibid.).

62 Ibid.

${ }^{63}$ Ibid. A estos ejemplos Nietzsche suma los siguientes: "Nosotros decimos «la pócima está amarga» en vez de «excita en nosotros una sensación particular de esa clase»; «la piedra es dura» como si «duro» fuese algo distinto de un juicio nuestro" (Ibid.).

64 Para un estudio detallado de la recepción que Nietzsche realiza de Gerber véase los estudios de Anthonie Meijers, Martin Stingelin y Claudia Crawford antes señalados en la nota 8. A pesar de que estos trabajos toman las ediciones Kröner y Musarion de Descripción de la retórica antigua, sus conclusiones respecto a la influencia de Gerber sobre este escrito póstumo siguen siendo válidas en la medida en que el parágrafo 3 de estas ediciones no guarda diferencias con el parágrafo 3 de la edición crítica de ColliMontinari. 
muestra un aspecto de la misma que se propone como preponderante sobre otros. Aquí también, estas transposiciones impropias varían de acuerdo con si son metáforas, metonimias o sinécdoques. Todo esto conlleva necesariamente a un empobrecimiento y a una simplificación -cuando no a una deformación de la sensación original- que torna inviable la posibilidad de un lenguaje de orden correspondentista.

De este modo, si la génesis lingüística se desarrolla a través de la acción de los tropos, éstos pierden inevitablemente su carácter de meros ornamentos. Los tropos "(...) no son ni formas secundarias o derivadas del lenguaje, ni un simple ornato estético, ni una denominación literal figurada que deriva de un significado propio". ${ }^{65} \mathrm{Si}$ bien es cierto que esta tesis no es nueva, dado que Vico, Rousseau, Hamman y Herder la habían defendido con anterioridad; Nietzsche la lleva hasta sus últimas consecuencias al entender al tropo como el paradigma lingüístico por excelencia. En este sentido, al estar a la base del proceso de formación del lenguaje, los tropos son lo más característico, lo más propio del lenguaje. He ahí el motivo por el cual Nietzsche no deja de insistir en que "el lenguaje es retórica", "(...) pues los tropos constituyen su propia esencia, ya que no se puede hablar de un lenguaje «natural», referencia pura de cualquier forma del lenguaje". ${ }^{66}$ De esta manera, la atención del estudio del lenguaje es desplazada desde la adecuación a un referente extralingüístico aspecto o función del lenguaje que ahora es negada- hasta los recursos intralingüísticos de los tropos y las figuras retóricas.

Sólo atendiendo detenidamente a esta concepción genético-lingüística de orden tropológica se puede comprender cabalmente la idea de Nietzsche de que el lenguaje no transmite una episteme sino una doxa. Si se producen transposiciones impropias en cada uno de los pasos de la génesis lingüística con el consecuente empobrecimiento y simplificación de los elementos particularísimos de la sensación primera y el inevitable cambio en el material de las distintas representaciones-, el lenguaje se revela como incapaz de expresar lo que las "cosas o eventos" son en sí mismos. Sin embargo, esta limitación del lenguaje señala lo que es verdaderamente importante y en dónde debe colocarse la atención: en la persuasión, es decir, en “(...) la fuerza del

\footnotetext{
${ }^{65}$ De Santiago Guervós, Luis Enrique: Arte y poder. Aproximación a la estética de Nietzsche, p. 394.

66 Ibid.
} 
convencimiento, que es lo que en realidad ha de jugar un papel esencial en nuestra percepción del mundo y en nuestra comunicación con los demás". ${ }^{67}$ Así Nietzsche lo sintetiza hacia el final del parágrafo tercero de Descripción de la retórica antigua:

No son las cosas las que penetran en la conciencia, sino la manera en que nosotros estamos ante ellas, el $\pi \iota \theta \alpha \nu$ ó [poder de persuasión]. Nunca se capta la esencia plena de las cosas. Nuestras expresiones verbales nunca esperan a que nuestra percepción y nuestra experiencia nos hayan procurado un conocimiento exhaustivo, y de cualquier modo respetable sobre la cosa. Se producen inmediatamente cuando la excitación es percibida. En vez de la cosa, la sensación sólo capta una señal (Merkmal). Este el primer punto de vista: el lenguaje es retórica, pues sólo pretende transmitir (übertrangen) una $\delta o ́ \xi \alpha$, y no una $\epsilon \pi\left\llcorner\sigma \tau \eta \dot{\mu} \mu{ }^{68}\right.$

Así, Nietzsche da la razón a Platón y Aristóteles cuando éstos sostienen que la retórica no puede versar sino sobre la doxa y nunca sobre la verdad (episteme). El filósofo alemán acepta este reproche, “(...) pero sólo para disolverlo en una especie de escepticismo respecto a la relación entre el lenguaje y la epistemología". ${ }^{69}$ En efecto, Nietzsche niega -como consecuencia de su postura cognoscitiva-lingüística- que el hombre sea capaz de captar y expresar cómo las cosas son verdaderamente en sí mismas. De este modo, el autor alemán lleva adelante una rehabilitación de la vía retórica del problema de la apariencia, que establece un nuevo marco desde dónde abordar las cuestiones fundamentales sobre el mundo y su justificación misma. Nuevamente toma fuerza aquí aquella tesis ya presente en El Nacimiento de la Tragedia que "toda vida se basa en la apariencia”70, “(...) aunque el contenido del significado de

67 Ibid.

${ }^{68}$ Nietzsche, F., Escritos sobre retórica, pp. 91-92.

${ }^{69}$ De Santiago Guervós, L. E., Arte y poder. Aproximación a la estética de Nietzsche, p. 387.

${ }^{70}$ Nietzsche, Friedrich: Obras completas. Volumen I. Escritos de Juventud (ed. Diego Sánchez Meca, trad., intr. y notas de Joan B. Llinares, Diego Sánchez Meca y L. E. Santiago de Guervós): El Nacimiento de la Tragedia, Madrid, Tecnos, 2011, p. 333. 
«apariencia» habría sufrido un cierto desplazamiento: desde la apariencia bella del arte a la apariencia doxásica de la retórica". ${ }^{71}$

\section{Conclusión}

De todo lo expuesto hasta aquí, se puede concluir que el estudio de Descripción de la retórica antigua reviste un papel de gran importancia en la comprensión de la configuración de la perspectiva retórico-lingüística del joven Nietzsche por cuatro razones principales:

Primero, Nietzsche define varios elementos de su concepción sobre el lenguaje en Descripción de la retórica antigua. En efecto, es posible encontrar desarrollados conceptualmente muchos de los elementos centrales de la postura lingüística nietzscheana a lo largo de estos apuntes de clases, que no lo están en otros escritos del período de juventud. Claros ejemplos de esto lo son las definiciones de tropo retórico, de figura retórica, de metáfora, de metonimia, de sinécdoque, entre otros. Ello dispensa al intérprete de caer en interminables y discutibles especulaciones conceptuales y colocar la atención en otros aspectos de la laboriosa tarea de reconstrucción del pensamiento del filósofo alemán.

El segundo motivo radica en la posibilidad de analizar una de las primeras apropiaciones definidas que el pensador alemán realiza de las fuentes retóricas. En Descripción de la retórica antigua se puede apreciar cómo la perspectiva retórico-lingüística toma forma gradualmente a la luz de la confluencia de la tradición de filología clásica de Spengel y Volkmann -con sus estudios cronológicos sobre las definiciones de retórica del mundo griego y romano- y de la tradición filosófica de Schopenhauer, Lange, Hartmann y Gerber. Ello permite advertir el modo en cómo el pensador alemán recibe y hace uso de las obras de otros autores de su época. En este sentido, se puede reconocer un doble mérito en su ejercicio hermenéutico. Por un lado, Nietzsche deja que la tradición hable en sus textos; logra entablar un fecundo diálogo con ella desde su particular situación y horizonte histórico. De esta forma, su interpretación de la retórica constituye un capítulo más en la historia de la retórica. Por el otro lado, también es preciso señalar la manera en que Nietzsche somete las opiniones y las posturas de varios pensadores a una

\footnotetext{
${ }^{71}$ De Santiago Guervós, L. E., Arte y poder. Aproximación a la estética de Nietzsche, p. 387. La cursiva es propia.
} 
profunda reelaboración y trasformación acorde a sus preocupaciones e intereses por el lenguaje como lugar de la crítica a la cultura y a la filosofía.

La tercera razón yace en que la lectura de los fragmentos de Descripción de la retórica antigua concernientes al análisis genético de la formación del lenguaje evidencia cómo la retórica comienza a ser concebida por Nietzsche más allá de una mera "aplicación persuasiva del lenguaje". La retórica se acerca aquí al segundo sentido propuesto por de Santiago Guervós líneas atrás, es decir, "como clave metódica para la genealogía y pragmática del lenguaje." Pasa a convertirse así en el método de abordaje por excelencia a fin de revelar su propio origen inconsciente en el lenguaje y finalmente, poder realizar de esta forma una reconstrucción del lenguaje como un producto de artes retóricas inconscientes. Si bien es cierto que Nietzsche lleva adelante un ejercicio ejemplar y sistemático de este método poco tiempo más tarde en Sobre verdady mentira en sentido extramoral al describir las distintas fases de la génesis del lenguaje en términos de tropos y figuras retóricas, el pensador alemán ya adelanta claramente este uso genealógico en Descripción de la retórica antigua. Se puede advertir así “(...) cómo Nietzsche, al concentrarse sobre todo en el carácter filosófico y epistemológico de los tropos y las figuras retóricas, soslaya claramente el significado popular de la retórica como mera elocuencia" 72 para transformar la retórica en un novedoso y radical método de indagación genealógica desde los tempranos Cursos de retórica.

Finalmente, como último aspecto a señalar, es posible observar que los principales elementos de la teoría lingüística nietzscheana ya se encuentran presentes -aunque algunos de ellos se encuentran desarrollados sólo de forma parcial y otros son mencionados únicamente a título enunciativo- en Descripción de la retórica antigua: 1) el lenguaje es esencialmente metafórico y las palabras son tropos desde su mismo comienzo; 2) el lenguaje es una especie de arte inconsciente; 3) la génesis del lenguaje consiste en un proceso que va de imagen en imagen; y 4) el lenguaje es incapaz de describir la realidad o la esencia de las cosas. ${ }^{73}$ De este modo, se gesta un modelo lingüístico que concibe al lenguaje

\footnotetext{
72 Ibid., p. 393.

${ }^{73}$ Cfr. Crawford, Claudia, op. cit., p. 205. Claudia Crawford propone estos cuatro puntos fundamentales como ejes centrales de la concepción retórica del lenguaje del pensador alemán a fin de identificar con precisión los elementos que Nietzsche toma de otros
} 
como el resultado de "artes puramente retóricas" de carácter inconsciente. Los medios de estas artes retóricas inconscientes, es decir, los llamados tropos o artificios retóricos, intervienen en la génesis del lenguaje desde el comienzo, mucho antes de su uso y perfeccionamiento consciente. La formación del lenguaje se explica, así, como un proceso gradual de traslación de orden trópico de una esfera a otra de distinta naturaleza. Es decir, el movimiento entre las distintas etapas lingüísticas -estímulo nervioso, imagen o figura, sonido o palabra y concepto- se comprende como transposiciones impropias que pueden ser de diferente tipo: metáforas, metonimias o sinécdoques.

\section{Bibliografía}

- Aristóteles, El arte de la retórica, trad. E. Ignacio Granero, Buenos Aires, Eudeba (2da ed), 2015.

- Crawford, Claudia, The beginnings of Nietssche's theory of language, Berlin, De Gruyter, 1988.

- De Santiago Guervós, Luis Enrique, "El poder de la palabra: Nietzsche y la retórica" en Nietzsche, Friedrich: Escritos sobre retórica, trad. Luis Enrique de Santiago Guervós, Madrid, Trotta, 2000, pp. 9-77.

- De Santiago Guervós, Luis Enrique: "Nietzsche y los límites del lenguaje: la fuerza del instinto", en Philosophica Malacitana: Actualidad de Nietzsche en el 150 aniversario de su nacimiento, 1994, Suplemento núm. 2, pp. 115-130.

- De Santiago Guervós, Luis Enrique, Arte y poder. Aproximación a la estética de Nietzsche, Madrid, Trotta, 2004.

- Fava, Fernando, "Orígenes de la crítica nietzscheana del conocimiento a partir del lenguaje” en Open Insight, Volumen VIII, núm. 13 (enero-junio 2017), pp. 161-188.

- Janz, Curt Paul, Friedrich Nietzsche. 2. Los diez años de Basilea, trad. Jacobo Muñoz e Isidoro Reguera, Madrid, Alianza Universidad, 1981.

- Liddell, Henry George y Scott, Robert, A Greek-English Lexicon. Revised and augmented throughout by Sir Henry Stuart Jones, with the assistance of Roderick McKenzie. Oxford, Clarendon Press, (9na. ed.), 1996.

autores y poder así determinar su verdadero alcance y valor en el marco general de su obra de juventud. 
- Locke, John, Ensayo sobre el entendimiento bumano, trad. Edmundo O'Gorman, México, Fondo de Cultura Económica, (2da ed.), 2005.

- Meijers, Anthonie, „Gustav Berger und Friedrich Nietzsche. Zum historischen Hintergrund der sprachphilosophischen Auffassungen des frühen Nietzsche“, Nietzsche Studien, 1988, N 17, pp. 369-390.

- Meijers, Anthonie y Stingelin, Martin, „Konkordanz zu den wörtlichen Abschriften und Übernahmen von Beispielen und Zitaten aus Gustav Gerber. Die Sprache als Kunst (Bomberg, 1871) in Nietzsches Rhetorik-Vorlesung und in Über Wahrheit Lüge im aussermoralischen Sinne“, Nietəsche Studien, 1988, núm. 17, pp. 350-368.

- Nietzsche, Friedrich, "Nietzsche's 'Lecture Notes on Rhetoric': A Translation", Philosophy \& Rhetoric. (trad. Carole Blair). Vol. 16, N 2. Penn State University Press, 1983, pp. 94-129. Stable URL: http://www.jstor.org/stable/40237356.

- Nietzsche, Friedrich, Escritos sobre retórica, trad. Luis Enrique de Santiago Guervós, Madrid, Trotta, 2000.

- Nietzsche, Friedrich, Nietæsche's Werke (ed. A. Kröner), Leipzig, 1912. Vols. 17, 18, 19 (Philologica, 1, 2, 3), 1912-1913.

- Nietzsche, Friedrich, Nietzsches gesammelte Werke (Vorlesungen 1872-1876), vol. 5, München, Musarion, 1922.

- Nietzsche, Friedrich, Obras completas. Volumen I: Escritos de Juventud, ed. Diego Sánchez Meca, trad., intr. y notas de Joan B. Llinares, Diego Sánchez Meca y Luis E. de Santiago Guervós, Madrid, Tecnos, 2011.

- Nietzsche, Friedrich, Werke, Kritische Gesamtausgabe (KGW), Abd. 2, Bd. 4: Vorlesungsaufzeichnungen: WS 1871-72 - WS 1874-75, Walter Gruyter, Berlin, 1995.

- Ricoeur, Paul, La metáfora viva, trad. Agustín Neira, Madrid, Trotta-Cristiandad (2da ed.), 2001.

- Sánchez, Sergio, "Lenguaje, conocimiento y verdad en la filosofía del joven Nietzsche: los póstumos de 1873 y sus fuentes". Nombres. Revista de Filosofía, 1999, núm. 13-14, pp. 181-214.

- Sánchez, Sergio, "Los escritos de Nietzsche sobre retórica en edición española", Nombres. Revista de Filosofía, 2000, núm. 15, pp. 293-297.

- Sánchez, Sergio, El problema del conocimiento en la filosofía del joven Nietzsche: los póstumos del periodo 1867-1873, Córdoba, Universitas, 2003. 
- Schnyder, Peter, "Ursprungskritik Nietzsches Anfänge und die Ursprünge der Rhetorik", Nietzsche-Studien. Internationales Jahrbuch für die Nietzsche-Forschung, 2013, N 42, Walter de Gruyter, pp. 1-20.

- Stingelin, Martin, „Nietzsche Wortspiel als Reflexion auf poet(olog)ische Verfahren“, Nietzsche Studien, 1988, No 17, pp. 336-349.

Recibido: 6/2019. Aceptado: 10/2019. 